\title{
Spatial and thematic assessment of object-based forest stand delineation using an OFA-matrix
}

\author{
A. Hernando ${ }^{\mathrm{a}, *}$, D. Tiede ${ }^{\mathrm{b}}$, F. Albrecht ${ }^{\mathrm{b}}$, S. Lang ${ }^{\mathrm{b}}$ \\ a Technical University of Madrid (U.P.M.), E.T.S.I. de Montes, Silvanet Research Group, Ciudad Universitaria s/n, 28040 Madrid, Spain \\ ${ }^{\mathrm{b}}$ Centre for Geoinformatics Z_GIS, Salzburg University, Schillerstrasse 30, 5020 Salzburg, Austria
}

\section{A R T I C L E I N F O}

\section{Article history:}

Received 23 September 2011

Received in revised form 3 March 2012

Accepted 15 May 2012

\section{Keywords:}

Forest management

Stands delineation

Object Fate Analysis

Spatial accuracy

Thematic accuracy

OFA-matrix

\begin{abstract}
A B S T R A C T
The delineation and classification of forest stands is a crucial aspect of forest management. Object-based image analysis (OBIA) can be used to produce detailed maps of forest stands from either orthophotos or very high resolution satellite imagery. However, measures are then required for evaluating and quantifying both the spatial and thematic accuracy of the OBIA output. In this paper we present an approach for delineating forest stands and a new Object Fate Analysis (OFA) matrix for accuracy assessment. A two-level object-based orthophoto analysis was first carried out to delineate stands on the Dehesa Boyal public land in central Spain (Avila Province). Two structural features were first created for use in class modelling, enabling good differentiation between stands: a relational tree cover cluster feature, and an arithmetic ratio shadow/tree feature. We then extended the OFA comparison approach with an OFA-matrix to enable concurrent validation of thematic and spatial accuracies. Its diagonal shows the proportion of spatial and thematic coincidence between a reference data and the corresponding classification. New parameters for Spatial Thematic Loyalty (STL), Spatial Thematic Loyalty Overall (STLOVERALL) and Maximal Interfering Object (MIO) are introduced to summarise the OFA-matrix accuracy assessment. A stands map generated by OBIA (classification data) was compared with a map of the same area produced from photo interpretation and field data (reference data). In our example the OFA-matrix results indicate good spatial and thematic accuracies (>65\%) for all stand classes except for the shrub stands (31.8\%), and a good STL OVERALL (69.8\%). The OFA-matrix has therefore been shown to be a valid tool for OBIA accuracy assessment.
\end{abstract}

(c) 2012 Elsevier B.V. All rights reserved.

\section{Introduction}

Appropriate management of a forest area is dependent on knowledge of its composition. The basic unit used for forest planning is the stand, which comprises any homogenous patch of vegetation that is distinct from adjacent stands in species composition, structure, and future management possibilities (Hernando et al., 2010). Stands have traditionally been delineated visually from aerial photographs by human pattern recognition, and then interpreted with the support of local field data and inventories (tree diameters, heights, crown sizes, etc.) and additional observations. This method is time consuming, subjective, and expensive. New cost-effective techniques are therefore required to supplement, and eventually replace, the traditional methods (Tiede et al., 2004; Petr et al., 2010; Pascual et al., 2008). Many recent studies have used object-based image analysis (OBIA) to characterise forest stands (Tiede et al., 2004; Petr et al., 2010; Radoux and

\footnotetext{
* Corresponding author. Tel.: +34 665816677.

E-mail addresses: ana.hernando@upm.es (A. Hernando), dirk.tiede@sbg.ac.at (D. Tiede), Florian.Albrecht@sbg.ac.at (F. Albrecht), Stefan.Lang@sbg.ac.at (S. Lang).
}

Defourny, 2007; Hay et al., 2005; Flanders et al., 2003; Laliberte et al., 2007; Laliberte et al., 2004). They achieved satisfactory results compared to pixel-based methods and have enhanced the utility and versatility of eCognition software (Definiens Imaging $\mathrm{GmbH}$, 2002). Latterly, most attempts at stand mapping have used Light Detection and Ranging (LiDAR) data, achieving good results in most cases (Tiede et al., 2004; Petr et al., 2010; Pascual et al., 2008; Wulder et al., 2008; Arroyo et al., 2010; Suarez et al., 2005). Airborne LiDAR data are, however, expensive and not always available. Fortunately, other alternatives are available for stand discrimination. Digital colour-infrared orthophotos $(50 \mathrm{~cm}$ resolution) have recently become available in Spain through the National Plan for Aerial Orthophotography (PNOA) (Gallego Priego et al., 2010). New specialised techniques are therefore required for stand mapping from orthophotos.

OBIA offers a relatively new approach for producing land cover maps, providing automated methods for the analysis of very high resolution images. In contrast to the traditional pixel-based approach, OBIA describes the imaged reality using spectral, textural, spatial, topological, and hierarchical object characteristics (Blaschke, 2010; Lang, 2008). Use of this new method, however, raises concerns about subsequent validation strategies, since the 